\title{
TERAPIA ANTIRRETROVIRAL: UM COMPARATIVO ENTRE CARACTERÍSTICAS EPIDEMIOLÓGICAS DE PACIENTES PORTADORES DE HIV
}

\author{
Claudinei Mesquita da SILVA ${ }^{1,2}$, Alex Sandro JORGE ${ }^{2,3}$, Jakeline Aparecida MATZECH ${ }^{1}$, Leyde Daiane de \\ 1 Centro Universitário da Fundação Assis Gurgacz. Cascavel, Paraná, Brasil. \\ 2 Universidade Estadual de Maringá. Maringá, Paraná, Brasil. \\ 3 Universidade Estadual do Oeste do Paraná. Cascavel, Paraná. Brasil. \\ 4 Centro Especializado em Doenças Infecto Parasitárias (CEDIP), Cascavel, Paraná, Brasil. \\ * Autor para correspondência: leydepeder@yahoo.com.br
} PEDER $^{1,2^{*}}$, Josana Dranka HORVATH ${ }^{4}$, Jorge Juarez Vieira TEIXEIRA ${ }^{2} \&$ Dennis Armando BERTOLINI ${ }^{2}$

DOI: http://dx.doi.org/10.18571/acbm.157

\section{RESUMO}

Introdução: Entre os anos de 1996 a 2012, o uso da TARV (terapia antirretroviral) evitou a morte de 6,6 milhões de pessoas com o Vírus da Imunodeficiência Humana (HIV)/Síndrome da Imunodeficiência Adquirida (aids) no mundo. Objetivos: Comparar as características epidemiológicas, clínicas e laboratoriais de pacientes portadores do vírus HIV/aids em relação ao uso da terapia antirretroviral. Materiais e Métodos: Estudo transversal e descritivo realizado com 1184 prontuários de pacientes com HIV/aids, atendidos no período de janeiro de 2005 a dezembro de 2014, em um centro de referência pertencente à $10^{\text {a }}$ Regional de Saúde (RS) do Paraná (PR), Brasil. Resultados: Observou-se que os pacientes com faixa etária de 18 e 39 anos, com diagnóstico maior que 5 anos, solteiros, com menor tempo de educação, com um ou nenhum parceiro sexual são os que possuem maior adesão à TARV, porém a diferença não foi significativa quando comparada aos indivíduos que não estão em tratamento. Pacientes em terapia possuem maiores níveis de linfócitos T CD4+ e menores de carga viral. Conclusão: Nenhuma das características sociodemográficas dos indivíduos atuou como facilitador à adesão. Pacientes em uso da TARV possuem significativamente menor carga viral, comparados aos não aderentes, reforçando a importância do tratamento em pacientes portadores de HIV/aids.

Palavras-chave: HIV; Terapia Antirretroviral de Alta Atividade; Adesão à Medicação.

\section{ABSTRACT}

Introduction: Between the years 1996-2012, the use of ART (antiretroviral therapy) prevented the death of 6.6 million people with the virus Human immunodeficiency (HIV)/Acquired Immunodeficiency Syndrome (aids) in the world. Objective: To compare the epidemiological, clinical and laboratory patients with HIV/aids in relation to the use of antiretroviral therapy. Materials and methods: A cross-sectional descriptive study conducted with 1184 records of patients with HIV/aids, served from January 2005 to December 2014, in a reference center belonging to the 10th Regional Health (RS) of Parana (PR), Brazil. Results: It was observed that patients aged 18 to 39 years, diagnosed more than 5 years, unmarried, less time education, with one or no sexual partner are those with greater adherence to ART, but the difference it was not significant when compared to individuals who are not in treatment. Patients on therapy have higher levels of CD4 + T lymphocytes and lower viral load. Conclusion: None of the sociodemographic characteristics of individuals acted as facilitator for membership. Patients on HAART had significantly lower viral load, compared to non-members, reinforcing the importance of treatment in patients with HIV/aids.

Keywords: HIV; Highly Active Antiretroviral Therapy; Medication Adherence. 


\section{Introdução}

O Vírus da Imunodeficiência Humana/Síndrome da Imunodeficiência Adquirida (HIV/aids) é considerado um problema de saúde pública mundial, atingindo pessoas independente da idade ou classe social (BRASIL, 2015). O número estimado de indivíduos que vivem com HIV/aids no plano mundial soma-se a um total de 36,7 milhões, sendo que aproximadamente 5700 novas infecções ocorrem ao dia. No ano de 2015, a doença acarretou a morte de cerca em 1,1 milhões de pessoas, segundo o Programa Conjunto da ONU sobre HIV/aids (Unaids) (UNAIDS, 2016). No Brasil, até o final de 2014, foram declarados 290.929 óbitos, além disso, cerca de 781 mil pessoas viviam com HIV/aids, representando uma prevalência de 0,39\% (BRASIL, 2015).

Com o avanço das pesquisas e devido à adesão aos antirretrovirais, a sobrevida dos pacientes portadores de HIV/aids tem aumentado (ALMEIDA et al, 2011), evitou-se a morte de 6,6 milhões de pessoas com aids no mundo entre os anos de 1996 a 2012 (UNAIDS, 2013). No Brasil, avalia-se que $80 \%$ das pessoas tem conhecimento sobre seu diagnóstico, $61 \%$ encontramse em acompanhamento, $44 \%$ estão em terapia antirretroviral e 33\% possuem carga viral abaixo do limite de detecção. O número de indivíduos em TARV aumentou nos últimos dez anos, passando de 125 mil no ano de 2002 para 313 mil no ano de 2012. Embora seja observado esse acréscimo, ainda são verificadas pessoas que não estão sendo tratadas, mesmo possuindo indicação de tratamento (BRASIL, 2013a).

Nesse contexto, a não adesão ou interrupção da TARV favorece o desenvolvimento de vírus com mutações, tornando-os resistentes aos medicamentos, podendo dar início a um novo ciclo de transmissão (BAGGALEY et al, 2010). Por essa razão, é recomendado o início precoce da TARV, com a finalidade de diminuir a transmissibilidade, principalmente no caso de casais soro discordantes (BRASIL, 2013b).

A TARV também possui benefícios no controle da replicação viral. A diminuição da carga viral em diferentes órgãos e fluídos corporais, mostra-se associada a uma menor transmissão do HIV em pacientes tratados adequadamente (DIEFFENBACH, 2012). Deste modo, o avanço do tratamento é essencial para por fim à epidemia, demonstrando que, entre as ferramentas de prevenção, a TARV eficaz oferece maior efeito preventivo (KARIM e KARIM, 2011). O sucesso da TARV fundamenta-se em garantir uma adequada adesão ao esquema de tratamento prescrito, o que é um grande desafio na atualidade. Portanto, o presente estudo teve por objetivo determinar as principais características epidemiológicas e laboratoriais dos pacientes portadores de HIV/aids, pertencentes à $10^{\mathrm{a}} \mathrm{RS}-\mathrm{PR}$, bem como, comparar essas características entre os pacientes que utilizam ou não terapia antirretroviral.

\section{Material e métodos}

Estudo de corte transversal realizado em um centro de referência para o diagnóstico de HIV/aids situado em Cascavel, estado do Paraná, Brasil, pertencente à $10^{\mathrm{a}}$ Regional de Saúde $\left(10^{\mathrm{a}}\right.$ RS), que atende 25 municípios divididos em sete microrregiões (Secretaria de Saúde do Estado do Paraná. Regionais SESA - 10a RS - Cascavel), com população total de 536.580 habitantes até de Julho de 2014 (IBGE - Paraná cities). A população foi constituída por 1256 indivíduos positivos para HIV que tiveram acesso ao serviço no período de janeiro de 2005 a dezembro de 2014.

Os exames sorológicos para diagnóstico do HIV foram realizados conforme as normas do Ministério da Saúde vigentes à época. Os últimos resultados referentes à contagem de linfócitos T CD4+, T CD8+ e a quantificação de carga viral para o HIV, foram obtidos dos respectivos prontuários dos pacientes. A determinação dos níveis de linfócitos T CD4+, T CD8+ e carga viral foram realizadas no Laboratório de Virologia Clínica da Universidade Estadual de Maringá, empregando para quantificação de linfócitos T a técnica de Citometria de Fluxo (BD Trucount ${ }^{\mathrm{TM}}$ Tubes), com o aparelho FACS Calibur (Becton-Dickinson, New Jersey, USA) e, para carga viral 
do HIV, utilizou-se o kit Abbott Real Time ${ }^{\mathrm{TM}}$ HIV-1 (ABBOTT GmbH \& Co. KG, Wiesbaden, Alemanha), com o aparelho m2000rt (Abbott Laboratórios do Brasil Ltda, Divisão de Diagnósticos).

Para fins de cálculos os pacientes foram divididos em dois grupos, àqueles em uso de terapia antirretroviral (aderentes) e os que não estavam em uso adequado (não aderentes). Foi considerado como parâmetro para avaliação da adesão ou não aos antirretrovirais a regularidade de aquisição dos medicamentos, por meio da retirada dos mesmos no Centro de Referência. Pacientes que retiraram todos os meses os medicamentos foram considerados como aderentes, enquanto os que não retiraram ou retiraram de forma não constante foram considerados como não aderentes. Os dados foram armazenados no programa Microsoft Excel ${ }^{\circledR}$ e, posteriormente, analisados no software STATA ${ }^{\circledR}$, versão 9.1. Os resultados foram expressos em médias, desviospadrão $( \pm \mathrm{DP})$ ou frequências. A associação entre as variáveis qualitativas foi realizada utilizandose os testes Qui-quadrado ou Teste Exato de Fisher. O estudo foi aprovado pelo Comitê de Ética em Pesquisa do Centro Universitário da Fundação Assis Gurgacz (Parecer n ${ }^{\circ}$ 1.397.212, de 28/01/2016).

\section{Resultados}

Do total de 1256 pacientes atendidos e diagnosticados com HIV/aids no período analisado, $1184(94,27 \%)$ eram residentes na região e pertencentes à $10^{a} \mathrm{RS}$. Dos dados disponíveis, 797 $(82,93 \%)$ eram aderentes à TARV e $164(17,07 \%)$ não aderentes à mesma. Em relação aos aderentes e não aderentes, verificou-se que a maior parte dos pacientes $(49,49 \%$ e 48,99\%, respectivamente), encontrava-se na faixa etária entre 18-39 anos. Em relação à etnia, mais de 60\% dos pacientes eram brancos e aproximadamente $40 \%$ eram solteiros, no entanto, grande porcentagem $(37,72 \%)$ de pacientes casados também apresentou a doença. Com relação à orientação sexual, $82,71 \%$ eram heterossexuais e $14,04 \%$, homossexuais. A grande maioria dos pacientes $(97,92 \%)$ adquiriu a infecção através da via sexual e aproximadamente $2 \%$ adquiriu por via vertical. Cerca $1 / 3(27,36 \%)$ da população em estudo relatou que tiveram mais de 5 parceiros sexuais nos últimos doze meses e 56,02\% referiu ter apenas o ensino fundamental. As demais características sociodemográficas estão sumarizadas na Tabela 1. 
Tabela 1: Características sociodemográficas dos indivíduos com HIV que realizaram ou não TARV, pertencentes à 10ª Regional de Saúde do estado do Paraná, Brasil, 2005-2014.

\begin{tabular}{|c|c|c|c|c|}
\hline Características & $\begin{array}{c}\text { Presença de } \\
\text { terapia } \\
\text { n }(\%) \\
\end{array}$ & $\begin{array}{c}\text { Ausência de } \\
\text { terapia } \\
\text { n (\%) } \\
\end{array}$ & $\begin{array}{l}\text { Total } \\
\text { n (\%) } \\
\end{array}$ & Valor de $p$ \\
\hline \multicolumn{4}{|l|}{ Faixa etária (anos) } & 0,37 \\
\hline $0-17$ & $19(2,17)$ & $1(0,51)$ & $20(1,86)$ & \\
\hline $18-39$ & $434(49,49)$ & $97(48,99)$ & $531(49,40)$ & \\
\hline $40-59$ & $357(40,71)$ & $81(40,91)$ & $438(40,74)$ & \\
\hline$\geq 60$ & $67(7,64)$ & $19(9,60)$ & $86(8,00)$ & \\
\hline \multicolumn{4}{|l|}{ Etnia } & 0,77 \\
\hline Branco & $582(67,28)$ & $128(65,64)$ & $710(66,98)$ & \\
\hline Parda & $249(28,79)$ & $59(30,26)$ & $308(29,05)$ & \\
\hline Preto & $30(3,47)$ & $6(3,08)$ & $36(3,40)$ & \\
\hline Outras & $4(0,46)$ & $2(1,03)$ & $6(0,57)$ & \\
\hline \multicolumn{4}{|c|}{ Tempo de diagnóstico de HIV (anos) } & 0,92 \\
\hline$\leq 2$ & $223(25,43)$ & $48(24,24)$ & $271(25,21)$ & \\
\hline $2-5$ & $234(26,68)$ & $55(27,78)$ & $289(26,88)$ & \\
\hline$>5$ & $420(47,87)$ & $95(47,98)$ & $515(47,91)$ & \\
\hline \multicolumn{4}{|l|}{ Transmissão do HIV } & 0,29 \\
\hline Sexual & $846(97,58)$ & $190(98,96)$ & $1036(97,92)$ & \\
\hline Drogas injetáveis & $1(0,12)$ & $1(0,52)$ & $2(0,19)$ & \\
\hline Leite materno & $1(0,12)$ & $0(0,00$ & $1(0,09)$ & \\
\hline Transmissão vertical & $18(2,08)$ & $1(0,52)$ & $19(1,80)$ & \\
\hline \multicolumn{4}{|l|}{ Estado civil } & 0,99 \\
\hline Solteiro & $419(48,27)$ & $88(47,06)$ & $507(48,06)$ & \\
\hline Casado & $325(37,44)$ & $73(39,04)$ & $398(37,72)$ & \\
\hline Divorciado & $83(9,56)$ & $17(9,09)$ & $100(9,48)$ & \\
\hline Viúvo & $41(4,72)$ & $9(4,81)$ & $50(4,74)$ & \\
\hline \multicolumn{4}{|c|}{ Comportamento sexual } & 0,88 \\
\hline Heterossexual & $704(82,44)$ & $162(83,94)$ & $866(82,71)$ & \\
\hline Homossexual & $122(14,29)$ & $25(12,95)$ & $147(14,04)$ & \\
\hline Bissexual & $28(3,28)$ & $6(3,11)$ & $34(3,25)$ & \\
\hline \multicolumn{4}{|c|}{ Número de parceiros nos últimos 12 meses } & 0,12 \\
\hline$\leq 1$ & $435(60,00)$ & $89(54,60)$ & $524(59,01)$ & \\
\hline$\overline{2}-5$ & $102(14,07)$ & $19(11,66)$ & $121(13,63)$ & \\
\hline$>5$ & $188(25,93)$ & $55(33,74)$ & $243(27,36)$ & \\
\hline \multicolumn{4}{|l|}{ Educação } & 0,99 \\
\hline$\leq 8$ anos & $479(56,09)$ & $107(55,73)$ & $586(56,02)$ & \\
\hline$>8$ anos & $375(43,91)$ & $85(44,27)$ & $460(43,98)$ & \\
\hline
\end{tabular}

$\mathrm{n}$ - número de pacientes

Verificou-se que a média dos níveis de linfócitos T CD4+ no grupo dos aderentes à TARV foi superior (543 \pm 329$)$ quando comparado aos não aderentes $(503 \pm 277)$, assim como, a relação TCD4+/TCD8+, que apresentou 0,62 \pm 1,21 e 0,56 \pm 1,16, respectivamente. Embora tenham sido verificados maiores níveis de células T CD4+ e maior relação T CD4+/CD8+ em pacientes que estavam fazendo uso da TARV, não foi verificada diferença estatística entre os grupos estudados $(p=0,72)($ Tabela 2). 
Tabela 2: Níveis de linfócitos T CD4+, T CD8+ e correlação CD4+/ CD8+ em pacientes com HIV que realizaram ou não TARV, pertencentes à 10ª Regional de Saúde do estado do Paraná, Brasil, 2005-2014.

\begin{tabular}{|c|c|c|c|c|c|c|}
\hline \multirow[t]{2}{*}{ Grupo } & \multirow{2}{*}{$\begin{array}{c}\text { Média CD4 } \\
\pm \text { DP } \\
\text { (cel./ mm3) }\end{array}$} & \multirow{2}{*}{$\begin{array}{c}\text { Média CD8 } \\
\pm \text { DP }(\text { cel./mm3) }\end{array}$} & \multirow{2}{*}{$\begin{array}{c}\text { Média } \\
\text { CD4/CD8 } \\
\text { 土 DP }\end{array}$} & \multicolumn{3}{|c|}{ CD4 (cel./mm3) } \\
\hline & & & & $\begin{array}{l}>200 \\
\text { n }(\%)\end{array}$ & $\begin{array}{c}\leq 200 \\
\mathrm{n}(\%)\end{array}$ & $\mathbf{p}$ \\
\hline $\begin{array}{c}\text { Presença de } \\
\text { terapia }\end{array}$ & $543 \pm 329$ & $834 \pm 607$ & $0,62 \pm 1,21$ & $671(87,37)$ & $97(12,63)$ & 0,72 \\
\hline $\begin{array}{l}\text { Ausência de } \\
\text { terapia }\end{array}$ & $503 \pm 277$ & $851 \pm 667$ & $0,56 \pm 1,16$ & $135(88,82)$ & $17(11,18)$ & \\
\hline
\end{tabular}

$\mathrm{n}$ - número de pacientes.

Constatou-se que a maioria dos pacientes $(69,63 \%)$ em TARV apresentou menor número de cópias do vírus (<50 cópias $/ \mathrm{mL}$ ) e que 3,90\% apresentaram mais de 1000 cópias $/ \mathrm{mL}$. No entanto, para os pacientes que não estavam realizando tratamento, 98,88\% dos pacientes possuíam mais de 1000 cópias do vírus HIV por $\mathrm{mL}$, o que demonstrou diferença estatística significativamente entres os grupos analisados $(p<0,05)$ (Tabela 3 ).

Tabela 3: Carga viral de pacientes com HIV que realizaram ou não TARV, pertencentes à $10^{\mathrm{a}}$ Regional de Saúde do estado do Paraná, Brasil, 2005-2014.

\begin{tabular}{cccc}
\hline $\begin{array}{c}\text { Carga viral do HIV } \\
\text { Cópias/mL }\end{array}$ & $\begin{array}{c}\text { Presença de terapia } \\
\mathbf{n}(\boldsymbol{\%})\end{array}$ & $\begin{array}{c}\text { Ausência de terapia } \\
\mathbf{n}(\boldsymbol{\%})\end{array}$ & Valor de p \\
\hline $\mathbf{5 0 0}$ & $555(69,63)$ & $2(1,22)$ & 0,001 \\
$\mathbf{5 0 - 1 0 0 0}$ & $211(26,47)$ & $4(2,44)$ & \\
$\mathbf{1 0 0 1 - 1 0 0 . 0 0 0}$ & $27(3,39)$ & $92(56,10)$ & \\
$>\mathbf{1 0 0 . 0 0 0}$ & $4(0,51)$ & $66(40,24)$ & \\
\hline
\end{tabular}

$\mathrm{n}$ - número de pacientes.

Para 33,91\% dos pacientes analisados, o tratamento foi prescrito com dois Inibidores da Transcriptase Reversa Análogos do Nucleosídeo (ITRN) associados a um Inibidor da Transcriptase Reversa não Análogo do Nucleosídeo (ITRNN). Esse mesmo esquema foi prescrito para 24,19\% dos pacientes, porém com medicamentos diferentes. Cerca 11,99\% dos pacientes receberam dois ITRNs associados a um Inibidor da Protease, esquema também prescrito para outros dois grupos de indivíduos $(8,75 \%$ e $5,72 \%)$. No entanto, cada um com dois Inibidores da Protease. O restante $(15,44 \%)$ dos pacientes analisados durante o período de estudo recebiam outros tipos de tratamento (Tabela 4 ). 
Tabela 4: Distribuição dos pacientes com HIV de acordo com a TARV, pertencentes à 10a Regional de Saúde do Estado do Paraná, Brasil, 2005-2014.

\begin{tabular}{ccc}
\hline Tratamento & $\mathbf{n}$ & \% \\
\hline 3TC+TENOF+EFAVIRENZ & 314 & 33,91 \\
AZT+3TC+EFAVIRENZ & 224 & 24,19 \\
AZT+3TC+KALETRA & 111 & 11,99 \\
AZT+3TC+ATAZANAVIR+RITONAVIR & 81 & 8,75 \\
3TC+TENOF+ATAZ+RITO & 53 & 5,72 \\
Outros Tratamentos & 143 & 15,44 \\
\hline Total & $\mathbf{9 2 6}$ & $\mathbf{1 0 0}$ \\
\hline
\end{tabular}

n - número de pacientes; 3TC - Lamivudina; TENOF - Tenofovir; AZT - Zidovudina; KALETRA Lopinavir/Ritonavir; ATAZ - Atazanavir; RITO - Ritonavir.

\section{Discussão}

A política implantada pelo Brasil na década de 1990 de acesso universal à terapia antirretroviral implicou na redução da mortalidade e internações, aumentando a expectativa de vida dos pacientes (GRANGEIRO et al, 2014). No entanto, mesmo com as melhorias que o tratamento pode trazer, alguns fatores podem influenciar na adesão à terapia (MÛNENE e EKMAN, 2014), como o esquecimento da administração dos medicamentos (LI et al, 2010), os efeitos adversos produzidos por eles e o tempo de tratamento (MÛNENE e EKMAN, 2014). Dessa forma, analisou-se as características sociodemográficas de pacientes portadores de HIV/aids, onde observou-se que a maioria apresentava faixa etária entre 18 e 39 anos. Resultados similares foram verificados em alguns estudos (MACHADO-ALBA; GONZÁLEZ-SANTOS; VIDALGUITART, 2011; REIS et al., 2011; GALVÃO et al., 2015), enquanto em outros (FONSECA et al., 2012; FIUZA et al., 2013; NOGUEIRA e SEIDL, 2016; PRADO et al., 2016), verificou-se maior diversidade de informações em relação à idade, com variação de 21 a 66 anos. Em vista dos resultados encontrados, pode-se observar que estes não estão em consonância com o perfil nacional, no qual a maior concentração dos casos de HV/aids no Brasil está atualmente em indivíduos com faixa etária entre 25 e 39 anos (BRASIL, 2015). Desse modo, avalia-se que a epidemia pode produzir danos significativos tanto na economia, quanto na área social, pois a faixa etária mais acometida corresponde à idade ativa da população (MUTABAZI-MWESIGIRE et al, 2014).

Em uma análise realizada sobre o perfil epidemiológico de pacientes com HIV atendidos no sul de Santa Catarina em 2010, verificou-se que, de 476 prontuários estudados, $64,9 \%$ dos pacientes estavam fazendo uso de terapia antirretroviral e $25,1 \%$, não estavam em tratamento (SCHUELTER-TREVISOL et al, 2013), o que coincide com o presente estudo. Além desses dados, o estudo reportou a principal via de aquisição do HIV como sendo a sexual (SCHUELTERTREVISOL et al, 2013), o que também foi claramente observado na presente pesquisa e na literatura (ROMEU et al., 2012; GALVÃO et al., 2015; PIMENTAA et al., 2015; PRADO et al., 2016). Verificou-se que os pacientes com etnia branca foram os mais acometidos no presente estudo, o que também foi encontrado em outras pesquisas (LOPES et al., 2011; ULTRAMARI et al., 2011; SCHUELTER-TREVISOL et al., 2013; PIMENTAA et al., 2015). As informações apresentadas também se mostraram coerentes com aquelas descritas pelo Ministério da Saúde (BRASIL, 2010), o qual relata que maioria dos casos de HIV/aids no Brasil abrange a cor branca, seguida de pardos e negros.

Em relação à escolaridade, alguns estudos demonstraram que houve quantidade significativa de indivíduos com HIV/aids que concluíram o ensino médio (GALVÃO et al., 2015; PIMENTAA et al., 2015; NOGUEIRA e SEIDL, 2016), diferente do encontrado na presente pesquisa e em demais literaturas (REIS et al., 2011; ULTRAMARI et al., 2011; LOPES et al., 


\section{ACTA \\ Biomedica Brasiliensia}

2011; SCHUELTER-TREVISOL et al., 2013; MÛNENE e EKMAN, 2014), que assinalam uma escolaridade menor ou igual a 8 anos de estudo.

Analisando os fatores associados a não adesão aos antirretrovirais em adultos com HIV/aids nos seis primeiros meses da terapia em Salvador, no ano de 2009, os resultados demonstraram que houve predomínio de pessoas solteiras ou que viviam sozinhas e indivíduos que se declararam heterossexuais (SILVA et al, 2015), resultados estes, semelhantes ao encontrado no presente estudo e na literatura (ALMEIDA et al., 2011; FIUZA et al., 2013). Este achado difere, portanto, dos obtidos em uma pesquisa realizada com pacientes acima de 50 anos (LOPES et al, 2011) e com gestantes infectadas pelo HIV (PIMENTAA et al, 2015), no qual a maioria, 41,9\% e $71,7 \%$ respectivamente, eram casados ou moravam com o companheiro. Em vista disso, pode-se articular que, a contaminação das parceiras, tanto por adultos jovens heterossexuais quanto por idosos heterossexuais, acontece devido às relações que ocorrem fora da convivência matrimonial, pois na confiança que tem em seus maridos, acabam por não utilizar preservativo nas relações sexuais, sendo então infectadas caso o parceiro esteja contaminado com o vírus (ANDRADE; SILVA; SANTOS, 2010).

Em virtude do que foi mencionado sobre a TARV, falhas na sua adesão podem causar danos ao sistema imune do infectado, que se estabelece em baixos níveis de linfócitos T CD4+, geralmente abaixo de 200 células $/ \mathrm{mm}^{3}$, tendo como resultado o progresso para aids (FELIX e CEOLIM, 2012). Com base nos dados apresentados neste estudo, a contagem de linfócitos T CD4+ foi maior nos pacientes que estavam realizando o tratamento, da mesma forma como relatado por GALVÃO et al (2015), onde 51,1\% das pessoas que aderiram à terapia apresentaram resultados superiores a 500 células $/ \mathrm{mm}^{3}$. Essa situação reflete a mesma encontrada em um estudo realizados com gestantes infectadas pelo HIV-1, onde o uso adequando da TARV foi capaz de aumentar os níveis de linfócitos T CD4+ (PIMENTAA et al, 2015). De forma semelhante, este achado é compatível com estudos realizados com idosos infectados pelo HIV/aids, no qual a minoria (16\%), de 142 pacientes, apresentou níveis menores que 200 células $/ \mathrm{mm}^{3}$, quando submetidos a TARV (ULTRAMARI et al, 2011). Sob o mesmo ponto de vista, constatou-se que a terapia antirretroviral também determinou uma resposta imunológica satisfatória em $72,3 \%$ dos pacientes com HIV/aids na Colômbia, alcançando uma contagem média inicial de linfócitos CD4 de 242,3 \pm 437,8 e uma contagem final de 408,9 \pm 235,3 (MACHADO-ALBA; GONZÁLEZ-SANTOS; VIDALGUITART, 2011).

Nesse contexto, ressalta-se que a terapia antirretroviral é composta pela associação de drogas antirretrovirais que, através da ação sobre o ciclo reprodutivo do vírus, diminuem a carga viral plasmática, evitando a infecção de novas células (MENÉNDEZ-ARIAS, 2013), porém são necessários altos níveis de adesão para haver diminuição da replicação do vírus no sangue circulante (FAUSTINO e SEIDL, 2010). Desse modo, baixos níveis de carga viral associam-se positivamente com o uso do tratamento (SCHUELTER-TREVISOL et al, 2013). Assim presente estudo mostra-se em conformidade com esta afirmativa, visto que a maioria dos pacientes que estavam em uso da TARV, apresentaram menor número de cópias do vírus por $\mathrm{mL}$, em relação aos que não estavam em terapia. Esse resultado também ocorreu em um estudo realizado com gestantes, no qual demostrou que o tratamento antirretroviral reduziu a carga viral das mesmas, fazendo com que a maioria $(58,7 \%)$ alcançassem a não detecção do vírus ( $<50$ cópias $/ \mathrm{mL}$ ) na $34^{\mathrm{a}}$ semana de gestação (PIMENTAA et al, 2015). Em conformidade, um estudo realizado na Colômbia sobre o uso de medicamentos antirretrovirais em pacientes com HIV/aids, também se mostrou coerente com os dados apresentados, demonstrando que a terapia foi eficaz em 73,6\% dos pacientes (carga viral <400 cópias/mL), que obtiveram carga viral inicial de 161,863 \pm 497.751 cópias/mL e carga final de $28.672 \pm 125.105$ cópias/mL (MACHADO-ALBA; GONZÁLEZSANTOS; VIDAL-GUITART, 2011).

O início da TARV deve conter a combinação de dois Inibidores da Transcriptase Reversa Análogos de Nucleosídeos (ITRN) e um Inibidor da Transcriptase Reversa Não Análogos de 
Nucleosídeos (ITRNN) (BRASIL, 2013c). Em relação ao esquema de tratamento prescrito na atual pesquisa, $59,1 \%$ das pessoas faziam uso desse esquema, corroborando também com outros estudos (ULTRAMARI et al., 2011; FONSECA et al., 2012; ROMEU et al., 2012; SILVA et al., 2015; PRADO et al., 2016), que além de apresentar pessoas que faziam uso do esquema inicial de tratamento preconizado, também apresentava, como no presente estudo, pessoas que utilizavam dois ITRNs associados a um Inibidor da Protease. Em concordância, um estudo realizado na China demonstrou que o uso combinado de ITRNs e ITRNNs são as principais formas de tratamentos utilizadas, porém, a utilização de Inibidores da Protease é incomum, devido ao custo desses medicamentos (JIAO et al, 2010). À vista disso, a combinação de antirretrovirais permite uma diminuição significativa na mortalidade de pessoas com HIV/aids, sendo a adesão uma barreira a ser superada (REGO e REGO, 2010).

\section{Conclusão}

A partir dos dados obtidos, foi possível verificar que a maioria dos pacientes atendidos no serviço pertencente à $10^{\mathrm{a}}$ Regional de Saúde do estado do Paraná, aderiram ao tratamento antirretroviral. Na comparação entre aderentes e não aderentes, verificou-se que nenhuma das características sociodemográficas dos indivíduos atuou como facilitador à adesão a TARV. Pacientes em uso da TARV, apresentam maiores níveis de Linfócitos T CD4+ e da relação CD4/CD8, porém sem significância estatística. No entanto, pacientes aderentes a TARV apresentaram carga viral significativamente menor $(<0,001)$ quando comparados aos não aderentes, o que mostra a importância do tratamento nos indivíduos infectados pelo HIV.

\section{Agradecimentos}

Ao Centro Especializado em Doenças Infecto Parasitárias (CEDIP) por fornecer todos os dados necessários para elaboração do presente estudo.

\section{Referências}

ALMEIDA, E. L.; ARAÚJO, G. B. S.; SANTOS, V. A.; BUSTORFF, L. A. C. V.; PEREIRA, A. V. L.; DIAS, M. D. Adherence to treatment and factors that interfere with HIV positive and those living with aids. Nurs J Minas Gerais. Vol 15 (2): 208-216, 2011.

ANDRADE, H. A. S.; SILVA, S. K.; SANTOS, M. I. P. O. Aids in elderly: reports of patients. Esc Anna Nery. Vol 14 (4): 712-719, 2010

BAGGALEY, R. F.; PETERSEN, M. L.; SOARES, M. A.; BOILY, M. C.; BASTOS, F. I. Human Immunodeficiency Virus: resistance to antiretroviral drugs in developing countries.

In: SOSA, A. J.; BYARUGABA, D. K.; AMÁBILE-CUEVAS, C. F.; HSUEH, P. R.; KARIUKI, S.; OKEKE, I. N.; editors. Antimicrobial Resistance in Developing Countries. Springer New York. 2010. p. 75-94.

BRASIL. Ministério da Saúde - Secretaria de Vigilância em Saúde - Departamento de DST, Aids e Hepatites Virais. Boletim Epidemiológico - AIDS 2010. Disponível em: <http://www.aids.gov.br/sites/default/files/anexos/publicacao/2010/45974/vers_o_final_15923.p df $>$. Acesso em: 12 de Agosto de 2016.

Ministério da Saúde - Secretaria de Vigilância em Saúde - Departamento de DST, Aids e Hepatites Virais. Epidemiological Bulletin HIV/AIDS, 2013a. Disponível em: 
<http://www.aids.gov.br/sites/default/files/anexos/publicacao/2013/55559/_p_boletim_2013_inte rnet_pdf_p_51315.pdf >. Acesso em: 12 de Agosto de 2016.

Ministério da Saúde - Secretaria de Vigilância em Saúde - Departamento de DST, Aids e Hepatites Virais, 2013b. Protocolo clínico e diretrizes terapêuticas para manejo da infecção pelo HIV em adultos. Disponível em: <http://conitec.gov.br/images/Protocolos/PCDT_Manejo-HIVAdultos_2013.pdf>. Acesso em: 12 de Agosto de 2016.

Ministério da Saúde - Secretaria de Vigilância em Saúde - Departamento de DST, Aids e Hepatites Virais, 2013c. Protocolo clínico e diretrizes terapêuticas para adultos vivendo com HIV/AIDS. Disponível em: <http:/www.aids.gov.br/sites/default/files/anexos/ publicação/2013/52934/_p_vers_atilde_o_preliminar_do_protocolo_cl_iacute_26118.pdf>.

Acesso em: 12 de Agosto de 2016.

Ministério da Saúde - Secretaria de Vigilância em Saúde - Departamento de DST, Aids e Hepatites Virais. Boletim Epidemiológico - AIDS, 2015. Disponível em: <http://www.aids.gov.br/sites/default/files/anexos/publicacao/2015/58534/boletim_aids_11_201 5_web_pdf_19105.pdf >. Acesso em: 12 de Outubro de 2016.

DIEFFENBACH, C. W. Preventing HIV transmission through antiretroviral treatment-mediated virologic suppression: aspects of an emerging scientific agenda. Curr Opin in HIV and AIDS. Vol 7 (2): 106-110, 2012.

FAUSTINO, Q. M.; SEIDL, E. M. F. Cognitive-Behavioral Intervention and Adherence to the Treatment by Persons with HIV/AIDS abstract. Psic Teor e Pesq. Vol 26 (1): 121-130. 2010;

FELIX, G.; CEOLIM, M. F. The profile of women with HIV/AIDS and their adherence to the antiretroviral therapy. Rev Esc Enferm USP. Vol 46 (4): 884-891, 2012.

FIUZA, M. L. T.; LOPES, E. M.; ALEXANDRE, H. D. O.; DANTAS, P. B.; GALVÃO, M. T. G.; PINHEIRO, A. K. B. Adherence to antiretroviral treatment: comprehensive care based on the care model for chronic conditions. Esc Anna Nery. Vol 17 (4): 740-748, 2013.

FONSECA, L. C.; MARTINS, F. J.; VIEIRA, R. C. P. A.; PEREIRA, R. M. C.; FERREIRA, A. S.; RAPOSO, N. R. B. Evaluation of inadequate anti-retroviral treatment in patients with HIV/ AIDS. Rev Soc Bras Med Trop. Vol 45 (2): 151-155. 2012.

GALVÃO, M. T. G.; SOARES, L. L.; PEDROSA, S. C.; FIUZA, M. L. T.; LEMOS, L. A. Quality of life and adherence to antiretroviral medication in people with HIV. Acta Paul Enferm. Vol 28 (1): 48-53, 2015.

GRANGEIRO, A.; ESCUDER, M. M.; CASSANOTE, A. J. F.; SOUZA, R. A.; KALICHMAN, A. O.; VELOSO, V.; et al. The HIV-Brazil Cohort study: Design, methods and participant characteristics. PLoS ONE. Vol 9 (5): 95673, 2014.

IBGE- Brazilian Institute of Geography and Statistics. Paraná cities. [Internet]. Disponível em: $<$ http://cidades.ibge.gov.br/xtras/uf.php?lang=\&coduf=41\&search= Parana>. Acesso em: 26 de Outubro de 2016.

JIAO, Y.; ZHANG, T.; WANG, S.; LIU, Q.; ZHOU, H.; LU, S.; et al. Profile of HIV-1 infected 
patients from an AIDS clinic in Beijing from 2007-2008. Curr HIV Res. Vol 8 (7): 515-520, 2010.

KARIM, S. S.; KARIM, Q. A. Antiretroviral prophylaxis: A defining moment in HIV control. The Lancet. Vol 378 (9809): 23-25, 2011.

LI, L.; LEE, S.; WEN, Y.; LIN, C.; WAN, D.; JIRAPHONGSA, C. Antiretroviral therapy adherence among patients living with HIV/AIDS in Thailand. Nurs Health Sci. Vol 12 (2): 212 $220,2010$.

LOPES, P. S. D.; SILVA, M. M. G.; TORRES, I. C.; STADÑIK, C. M. B. Quality of life in HIVpositive patients over 50 years of age. Revista Da AMRIGS. Vol 55 (4): 356-360, 2011.

MACHADO-ALBA, J. E.; GONZÁLEZ-SANTOS, D. M.; VIDAL-GUITART, X. Effectiveness of antiretroviral treatment in patients from Pereira and Manizales. Rev Salud Pública. Vol 13 (3): 492-503, 2011.

MENÉNDEZ-ARIAS, L. Molecular basis of human immunodeficiency virus type 1 drug resistance: overview and recent developments. Antiviral Research. Vol 98 (1): 93-120, 2013.

MÛNENE, E.; EKMAN, B. Does duration on antiretroviral therapy determine health-related quality of life in people living with HIV? A cross-sectional study in a regional referral hospital in Kenya. Global Health Action. Vol 7 (1): 23554, 2014.

MUTABAZI-MWESIGIRE, D.; SEELEY, J.; MARTIN, F.; KATAMBA, A. Perceptions of quality of life among Ugandan patients living with HIV: a qualitative study. BMC Public Health. Vol 14: 343, 2014.

NOGUEIRA, G. S.; SEIDL, E. M. F. Association between Illness Perception and Anxiety, Depression and Self-Effi cacy in People with HIV/AIDS. Temas em Psicol. Vol 24 (2): 595-608, 2016.

PIMENTAA, A. T. M.; DUARTEB, G.; COUTO-FERNANDEZC, J. C.; CORREAD, I. A.; MELLIE, P. P. S.; QUINTANA, S. M. HIV-infected pregnant women attending reference service: clinical and sociodemographic features. Rev de Atenção à Saúde. Vol 13 (45): 20-25, 2015.

PRADO, C. G.; PODESTÁ, M. H. C. M.; SOUZA, L. P. T.; SOUZA, W. A; FERREIRA, E. B. Pharmacoterapeutic follow-up of HIV-positive patients at a Dispensing Antiretroviral Medicines Unit. Rev da Univ Val do Rio Verde. Vol 14 (2): 562-576, 2016.

REGO, S. R. M.; REGO, D. M. S. Association between the usage of alcohol by HIV patients and the adherence to the antiretroviral drug treatment: a literature review. J Bras Psiquiatr. p. 70 $3,2010$.

REIS, R. K.; SANTOS, C. B.; DANTAS, R. A. S.; GIR, E. Quality of life, sociodemografic factors and sexuality of people living with HIV/aids. Texto Contexto Enferm. Vol 20 (3): 565-575, 2011.

ROMEU, G. A.; TAVARES, M. M.; CARMO, C. P.; MAGALHÃES, K. N.; NOBRE, A. C. L.; MATOS, V. C. Assessment of Adherence to Antiretroviral Therapy for Patients with HIV. Rev 
Bras Farm Hosp Serv Saúde. Vol 3 (1): 37-41, 2012.

SCHUElTER-TREVISOL, F.; PUCCI, P.; JUSTINO, A. Z.; PUCCI, N.; SILVA, A. C. B. Epidemiological profile of HIV patients in the southern region of Santa Catarina state in 2010. Epidemiol. Serv. Saúde. Vol 22 (1): 87-94, 2013.

Secretaria de Saúde do Estado do Paraná. Regionais SESA - 10 $0^{\mathrm{a} S}$ - Cascavel [Internet]. Disponível em: <http://www.saude.pr.gov.br/modules/conteudo/conteudo. php?conteudo=2762>. Acesso em: 26 de Outubro de 2016.

SILVA, J. A. G.; DOURADO, I.; BRITO, A. M.; SILVA, C. A. L. Factors associated with nonadherence to antiretroviral therapy in adults with AIDS in the first six months of treatment in Salvador, Bahia State, Brazil. Cad Saúde Pública. Vol 31(6): 1188-1198, 2015.

ULTRAMARI, L.; MORETTO, P. B.; GIR, E., CANINI, S. R. M. S.; TELES, S. A.; GASPAR, J.; et al. Clinical and epidemiological profile of the infection by HIV/aids in elderly. Rev Eletr Enf. Vol 13 (3): 405-412, 2011.

UNAIDS. Report on the global AIDS epidemic 2013 [Internet]. Disponível em: <http://www.unaids.org/sites/default/files/media_asset/UNAIDS_Global_Report_2013_en_1.pdf >. Acesso em: 12 de Agosto de 2016.

UNAIDS. Aids by numbers 2016. Disponível em: <http://www.unaids.org/sites/default/files/media_asset/AIDS-by-the-numbers2016 _en. Pdf>. Acesso em: 12 de Outubro de 2016. 